\title{
Environmental mercury exposure, semen quality and reproductive hormones in Greenlandic Inuit and European men: a cross-sectional study
}

\author{
Emina Mocevic ${ }^{1}$, Ina O Specht ${ }^{1}$, Jacob L Marott ${ }^{1}$, Aleksander Giwercman ${ }^{2}$, Bo AG Jönsson ${ }^{3}$, Gunnar Toft ${ }^{4}$, \\ Thomas Lundh ${ }^{3}$ and Jens Peter Bonde ${ }^{1}$
}

Several animal studies indicate that mercury is a male reproductive toxicant, but human studies are few and contradictory. We examined semen characteristics and serum levels of reproductive hormones in relation to environmental exposure to mercury. Blood and semen samples were collected from 529 male partners of pregnant women living in Greenland, Poland and Ukraine between May 2002 and February 2004. The median concentration of the total content of mercury in whole blood was $9.2 \mathrm{ng} \mathrm{ml}^{-1}$ in Greenland $(0.2-$ $\left.385.8 \mathrm{ng} \mathrm{ml}^{-1}\right), 1.0 \mathrm{ng} \mathrm{ml}^{-1}$ in Poland $\left(0.2-6.4 \mathrm{ng} \mathrm{ml}^{-1}\right)$ and $1.0 \mathrm{ng} \mathrm{ml}^{-1}$ in Ukraine $\left(0.2-4.9 \mathrm{ng} \mathrm{ml}^{-1}\right)$. We found a significantly positive association between the blood levels of mercury and serum concentration of inhibin $B$ in men from Greenland $(\beta=0.074,95 \%$ confidence interval $(\mathrm{Cl})=0.021$ to 0.126$)$ and in an analysis including men from all three regions $(\beta=0.067,95 \% \mathrm{Cl}=0.024$ to 0.110 ). The association may be due to beneficial effects of polyunsaturated fatty acids (PUFAs), which are contained in seafood and fish. No significant association $(P>0.05)$ was found between blood concentrations of mercury and any of the other measured semen characteristics (semen volume, total sperm count, sperm concentration, morphology and motility) and reproductive hormones (free androgen index (FAI), follicle-stimulating hormone (FSH), luteinizing hormone (LH), testosterone and $\mathrm{LH} \times$ testosterone) in any region. In conclusion, the findings do not provide evidence that environmental mercury exposure in Greenlandic and European men with median whole blood concentration up to $10 \mathrm{ng} \mathrm{ml}^{-1}$ has adverse effects on biomarkers of male reproductive health.

Asian Journal of Andrology (2013) 15, 97-104; doi:10.1038/aja.2012.121; published online 10 December 2012

Keywords: blood mercury concentration; environmental mercury exposure; male fertility; reproduction; reproductive hormones; semen characteristics; semen quality

\section{INTRODUCTION}

Mercury is suspected to have a negative impact on male fertility. ${ }^{1}$ The main contribution to human exposure in the general population is seafood, because the compound accumulates along the aquatic food chain. ${ }^{2}$ Thus, mercury concentrations are higher in Arctic populations due to a diet, where seafood and marine mammals are major constituents. ${ }^{3}$ Even though exposure to mercury is decreasing in Arctic populations, because of changes in diet, the Inuit continue to have blood mercury levels that exceed World Health Organization's (WHO) guidelines for total mercury intake of $2 \mu \mathrm{g} \mathrm{kg}^{-1}$ body weight per day and for methylmercury of $1.6 \mu \mathrm{gg}^{-1}$ body weight per week..$^{3-7}$ In Ukraine and Poland, blood mercury concentrations have been low and stable over a period of at least 12 years. $^{8-10}$ Nevertheless, global mercury emissions may be increasing because of burning of coal and fuel oil especially in Asia. ${ }^{11}$

In vitro studies have shown that mercury induces DNA breaks in spermatozo ${ }^{12}$ and lead to decreased sperm motility, dysfunction and viability. ${ }^{13-15}$ Reproductive toxicity of mercury has been described in several animal studies in which sperm motility, epididymal sperm count and normal sperm morphology decreased among rats, mice and monkeys after mercury exposure. ${ }^{16-20}$ Human studies are few and contradictory. It has been reported that seminal fluid mercury concentrations are correlated with abnormal sperm morphology and abnormal sperm motility. ${ }^{21}$ Furthermore, it has been observed that infertile and subfertile men have higher mercury levels than fertile men, ${ }^{22}$ and tubular atrophy and Sertoli-cell-only syndrome has been observed among infertile patients that have been exposed to mercury. ${ }^{23}$ Other studies have not reported male reproductive toxicity of mercury ${ }^{24-26}$ and no studies have found an association between mercury exposure and reproductive hormones. ${ }^{25,27,28}$ A limitation of most epidemiological studies is a small sample size. ${ }^{21-25,28}$ The populations are frequently infertility patients ${ }^{21,24,25,29}$ with inherent risk of biased findings ${ }^{30}$ and the outcome measures are broad, such as fertility, subfertility, spontaneous abortions, time to pregnancy and number of children. ${ }^{22,31-34}$.

The aim of this study was to investigate if blood concentrations of mercury $(\mathrm{Hg}$ ) are related to semen characteristics (semen volume, 
total sperm count, sperm concentration, sperm morphology, sperm motility) and serum levels of reproductive hormones (folliclestimulating hormone (FSH), luteinizing hormone (LH), free androgen index (FAI), inhibin $\mathrm{B}$, testosterone and $\mathrm{LH} \times$ testosterone). The study is based on three study populations with large exposure contrasts between and within countries. It is assumed that the majority of the mercury body burden is methylmercury $(\mathrm{MeHg})$, since the populations are environmentally exposed.

\section{MATERIAL AND METHODS}

\section{Study design}

Pregnant women and their male partners were consecutively recruited between May 2002 and February 2004 in three participating countries: Greenland, Poland and Ukraine. ${ }^{35}$ In the present study, only data from the male spouses are included. The local ethical committee in all participating countries approved the study and all participants signed an informed consent.

\section{Recruitment of study populations}

The male partners were approached by health professionals in the three countries and consecutively enrolled into the semen study when their pregnant wife attended a prenatal care visit until approximately 200 men at each site had agreed to participate. All participants were born in the country and at least 18 years of age at the time of enrollment. In Warsaw, Poland, the subjects were contacted at an outpatient clinic of the Gynaecological and Obstetric Hospital of the Warsaw School of Medicine or at physicians at a collaborating hospital from September 2002 through March 2004 (participation rate 197/690, 28.6\%). In Kharkiv, Ukraine, the males were approached at three maternity hospitals and eight antenatal clinics, respectively from April 2003 through February 2004 (participation rate 208/640, 33.5\%). In Greenland, 256 male spouses from 4 settlements and 15 municipalities were asked to participate in the semen study at the local hospital or health clinic in June 2002 through May 2004. The participation rate in Greenland was $77.7 \%$ (199/256). In total 604 men agreed to participate in the semen study and the overall participation rate was $38 \%$. Mercury was not measured in 72 men because of insufficient amount of blood left over from analysis of other xenobiotics. Furthermore, two individuals from the Ukrainian population were excluded because they were aged $<18$ years and one male from Greenland was excluded due to unreliable body mass index $(\mathrm{BMI})$ value $(\mathrm{BMI}<11)$. Thus, the final database included 529 men (194 men from Greenland, 178 men from Poland and 157 men from Ukraine, Figure 1).

\section{Data collection}

All sampling, interviews processing, storage and shipment of semen and blood samples were undertaken according to uniform study protocols, questionnaires and forms.

\section{Interviews}

The male interview included questions on lifestyle and occupational factors, urogenital disorders, sexual abstinence and issues regarding delivery of a semen sample. Information about smoking habits, diet, occupational exposure and alcohol consumption was obtained as well, but with reference to the period when the couple tried to become pregnant. The questionnaires were translated to the native language and back translated to English for correction of errors that occurred during the translation process. All answers in the questionnaires were typed in twice to minimize errors during the typing process. If inconsistencies occurred between the two sets

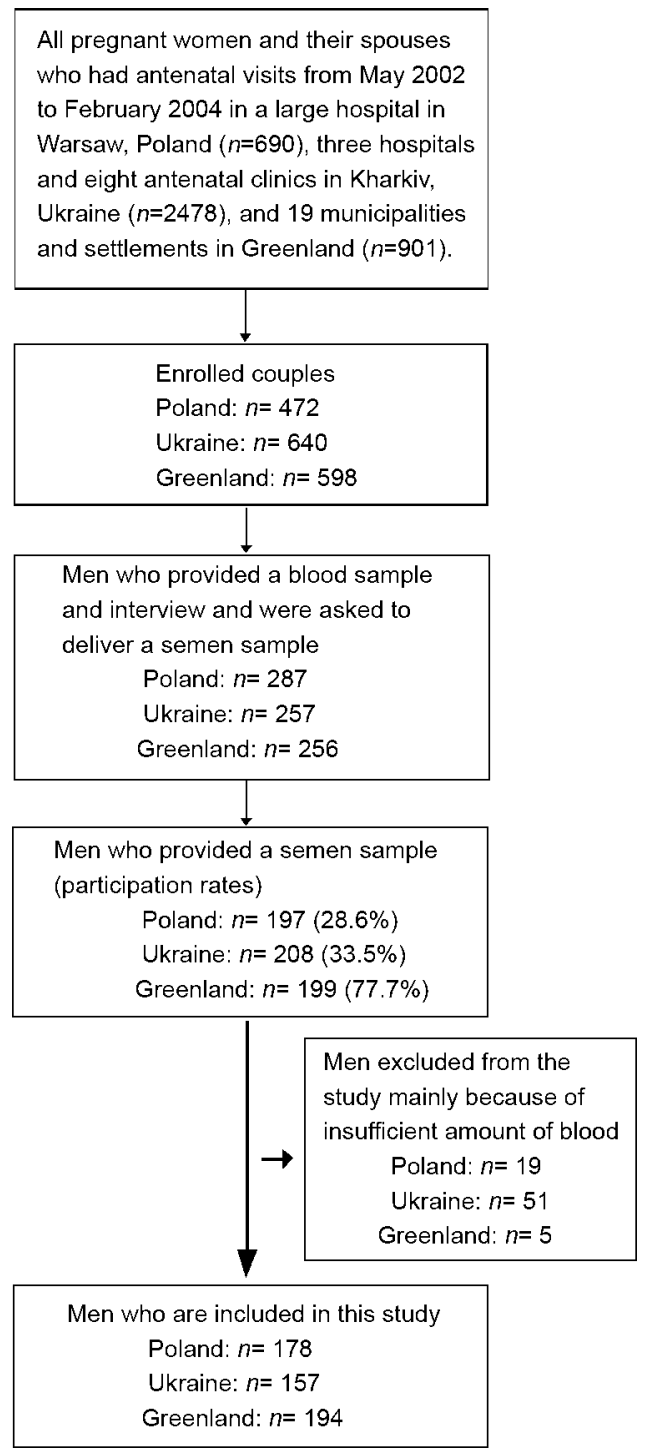

Figure 1 Flow chart of study population.

of typing, the original data was looked up and the typed in data was corrected.

\section{Mercury analysis}

Blood samples were collected by venepuncture within 1 week of the semen collection, except for 116 subjects from Greenland, which had taken a blood sample up to 1 year in advance. Mercury exposure and the hormonal profile were analysed from the blood samples. The determination of total mercury $(\mathrm{Hg})$ in whole blood was made in aciddigested samples by cold vapour atomic fluorescence spectrometry (PSA 10.035 Millenium Merlin 1631 system; PS Analytical, Kent, UK). The lower limit of detection (LOD) for $\mathrm{Hg}$ was $0.1 \mathrm{ng} \mathrm{ml}{ }^{-1}$. The analytical accuracy was checked against reference materials. For Seronorm Trace Elements Whole Blood L-3, lot. 0512627, (SERO AS, Billingstad, Norway) the result ( $\mathrm{ng} \mathrm{m}^{-1}$, mean \pm s.d.) obtained was $16.0 \pm 1.4(n=50) v s$. recommended $16-20$ and for human blood reference samples, lot. M-04-08 (Centre de Toxicologie du Quebec, International Comparison Program, Canada) 2.00 $0.11(n=50)$ vs. recommended 2.0. 


\section{Hormone analyses}

Serum concentrations of FSH and LH were measured using the UniCel DxI 800 Beckman Access Immunoassay system (Chaska, MN, USA). The LOD for both FSH and LH was $0.2 \mathrm{IU}^{-1}$ and the total coefficients of variation $(\mathrm{CV})$ were $3.5 \%$ at $5.5 \mathrm{IU} \mathrm{l}^{-1}$ and $4.1 \%$ at $23.6 \mathrm{IU} \mathrm{l}^{-1}$ for FSH and $5.2 \%$ at $4.0 \mathrm{IU}^{-1}$ and $2.3 \%$ at $19.3 \mathrm{IU}^{-1}$ for $\mathrm{LH}^{36}$ Serum testosterone levels were measured by means of a competitive immunoassay (Access; Beckman Coulter Inc., Fullerton, CA, USA). The LOD was at $0.35 \mathrm{nmol} \mathrm{l}^{-1}$ and the total $\mathrm{CV}$ for testosterone was $2.8 \%$ at $2.9 \mathrm{nmol} \mathrm{l}^{-1}$ and $3.2 \%$ at $8.1 \mathrm{nmol}^{-1}$. Sexual hormone-binding globulin serum concentrations were measured using fluoroimmunoassay (Immulite 2000; Diagnostic Products Corporation, Los Angeles, CA, USA). The LOD was $0.02 \mathrm{nmol}^{-1}$ and the total CV was $3.7 \%$ at $29 \mathrm{nmol} \mathrm{l}^{-1}$ and $6.7 \%$ at $85 \mathrm{nmol} \mathrm{l}^{-1} .^{36}$ Inhibin B levels were analysed using a specific immunometric method as previously described. ${ }^{36,37}$ The LOD for inhibin B was $15 \mathrm{ng} \mathrm{l}^{-1}$ and the total CV less than $7 \% .{ }^{36} \mathrm{FAI}$ is defined by whole blood testosterone divided by sexual hormone-binding globulin (testosterone/sexual hormonebinding globulin). All analyses were performed at Malmö and Lund University Hospitals, Sweden.

\section{Semen analysis}

The subjects were asked to abstain from sexual activities for at least $48 \mathrm{~h}$ before collecting the semen sample and to report the actual abstinence time. All samples were collected by masturbation in privacy in a room at the hospital or at the residence. If the sample was collected at the residence, the sample was kept close to the body to maintain a temperature of $37{ }^{\circ} \mathrm{C}$ when transported to the hospital immediately after collection. ${ }^{38}$ The samples were analyzed for concentration, motility and morphology according to manual for the project based on the WHO manual for basic semen analysis. ${ }^{39}$ The samples were analyzed by one researcher in each country. The researchers were trained in a quality-control program, which was set up specifically for this study and held at the Fertility Centre, Malmö University Hospital, Sweden. The median variation among investigators in estimating sperm concentration was $8.1 \%$ and motility (grade A and B) $11 \% .{ }^{40}$ The analyses of sperm motility were performed within $95 \mathrm{~min}$, and $95 \%$ of these were initiated within 60 min after ejaculation. ${ }^{35}$

Sperm concentration was determined in duplicate using an Improved Neubauer Hemacytometer (Paul Marienfeld, BadMergentheim, Germany). ${ }^{38}$ Sperm motility was classified in accordance with the WHO manual from 1999 by counting the proportion of fast progressive sperm (A), progressive sperm (B), nonprogressive motile sperm (C) and immotile sperm (D) among 100 spermatozoa within each of two fresh drops of semen. ${ }^{39}$ The samples were analysed twice and the mean was estimated. The analyses for concentration and motility took place at the central hospitals in Warsaw, Poland and in Kharkiv, Ukraine, whereas the semen samples from Greenland were analyzed at local hospitals in 19 municipalities and at one settlement. ${ }^{35}$ Evaluation of morphology according to the strict criteria was centralized and took place at the Fertility Centre, Malmö University Hospital, Sweden. Two technicians, who participated in a qualitycontrol program, stained and evaluated the morphology based on at least 200 sperm for each sample, as described by Toft et al. ${ }^{38}$.

\section{Data analysis}

We examined semen characteristics and serum concentrations of reproductive hormones as a function of mercury concentration by general linear models (PROC GLM procedure) using SAS 9.13 statistical software (SAS Institute Inc, Cary, NC, USA).

In the initial analyses, we divided the exposure variable, mercury, into tertiles due to large exposure contrasts between and within the countries. The Polish and Ukrainian populations were combined to one population termed 'European men' and a model including all populations termed 'all men'. To evaluate homogeneity of exposureresponse associations across populations, interactions between populations and $\log$ of exposure were tested and none were found. Study site was included as a covariate in both combined models and $P<0.05$ was considered as statistically significant.

To improve normality and homogeneity of variance, the exposure and the outcome variables were transformed by the natural logarithm (ln transformed). Homogeneity of variance and normal distribution of residuals was confirmed by visual inspection of the distribution of residuals. The association between mercury exposure in tertiles and continuous, and the 11 continuous outcome variables; sperm volume, sperm concentration, total sperm count, normal sperm morphology, poor sperm motility (nonprogressive and immotile sperm combined), FAI, inhibin $\mathrm{B}, \mathrm{FSH}, \mathrm{LH}$, testosterone and $\mathrm{LH} \times$ testosterone were analyzed.

Crude and adjusted associations between exposure and outcomes were analyzed. In the multiple general linear models the analyses were adjusted for known and suspected determinants of the outcome variables based on information from the literature. ${ }^{26,38,41-47}$ The following covariates were included: age (as a continuous variable), BMI (ln transformed continuous variable), period of sexual abstinence (days, ln transformed continuous variable), smoking (smoking at the time of conception: yes/no) and prior urogenital infections (yes/no). Alcohol consumption was excluded because of too many missing observations and lack of reliability. Time of blood sampling was not available among the Inuit population and is therefore not included in the analysis of the hormones. The analysis of sperm motility was restricted to samples analyzed within $1 \mathrm{~h}$ after collection ( $96 \%$ of the samples) and semen volume and total sperm count analyses were restricted to samples without spillage ( $90 \%$ of the samples). In the multiple analysis, the semen characteristics were adjusted for age, BMI, smoking, abstinence time and infections. The hormone outcomes were adjusted for age, BMI, smoking and infections. Tests for linear trends were also performed by general linear models, with exposure specified as a continuous variable. The results for linear trends are not adjusted for potential confounders; however, an adjusted analysis produced essentially unchanged estimates (data not shown).

\section{RESULTS}

The characteristics of the 529 adult men from Greenland, Poland and Ukraine are presented in Table 1. The average age in Greenland, Poland and Ukraine was 31.0, 30.4 and 26.8 years, respectively. The smoking habits differed within the countries, as $73.2 \%$ of the Inuit, $29.0 \%$ of the Polish and $64.5 \%$ of the Ukrainian men were smokers at the time when their wife became pregnant. Urogenital infections were more common in Greenland, where $84.6 \%$ of the adult males have had an infection compared to $18.5 \%$ in Poland and $8.9 \%$ in Ukraine. The difference in whole blood concentrations of mercury was large between the Inuit and European men, respectively with a median concentration of $9.2 \mathrm{ng} \mathrm{ml}^{-1}$ in Greenland (range $0.2-385.8 \mathrm{ng} \mathrm{ml}^{-1}$ ), $1.0 \mathrm{ng} \mathrm{ml}^{-1}$ in Poland (range $0.2-6.4 \mathrm{ng} \mathrm{ml}^{-1}$ ) and $1.0 \mathrm{ng} \mathrm{ml}^{-1}$ in Ukraine (range $0.2-4.9 \mathrm{ng} \mathrm{ml}^{-1}$ ) (Table 1).

The semen characteristics, hormone concentrations and the main results are presented in Tables $\mathbf{2 - 5}$. 


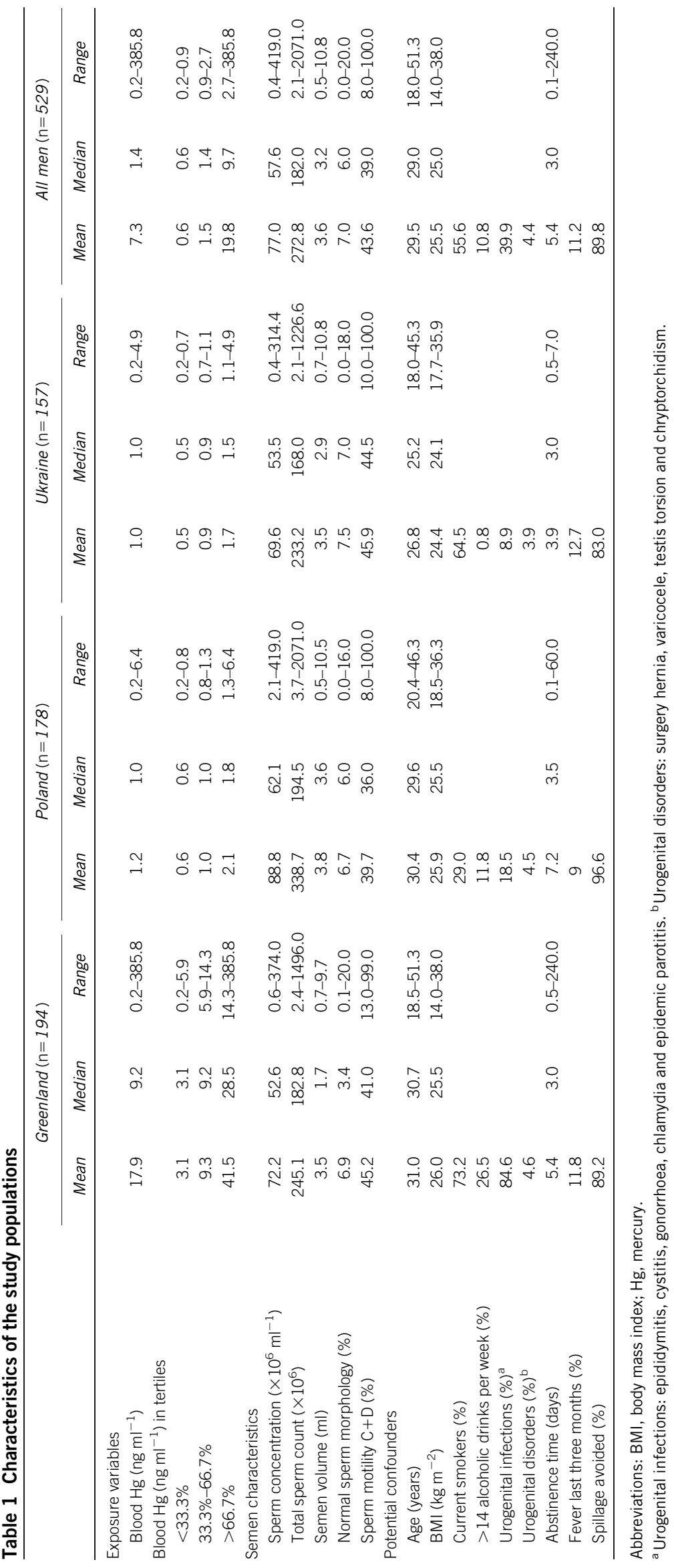


We found that inhibin B serum levels increased with increasing mercury exposure among the Inuit. The results were borderline significant $(P=0.048$ and $P=0.054)$ (Table 3$)$. When mercury was defined as a continuous variable, we found that inhibin B was associated with mercury exposure in the Inuit population and in the combined model including all three populations (Table 5). Among Greenlandic Inuit, inhibin B concentration significantly increased with $0.074 \%$ for every percent increase in mercury $(0.074 ; 95 \%$ confidence interval $(\mathrm{CI})=0.021$ to 0.126$)$ and in the combined model the inhibin B level increased with $0.067 \%$ for $1 \%$ increase in mercury concentration (0.067; 95\% CI=0.024 to 0.110 ) (Table 5). None of the remaining outcome measures were associated with mercury exposure, even after controlling for covariates (Tables 2-5).

\section{DISCUSSION}

This is, to our knowledge, the largest epidemiological study to date regarding hazardous effects of environmental mercury exposure on human semen quality and male reproductive hormones. We found positive associations between blood concentration of mercury and inhibin B serum levels among the Greenlandic Inuit and analyses including men from all three regions, but not in separate analyses of men from Warsaw and Kharkiv, where exposure levels were in average 10 -fold lower than in Greenland. Other outcome measures were not related to mercury exposure in any region. High serum concentration of inhibin B is reflecting high Sertoli cell activity and high sperm counts and thus the direction of the association between whole blood mercury and inhibin B is opposite relative to our a priory hypothesis. An in vitro study of immature rat Sertoli Cells showed markedly decreased inhibin B levels after mercury exposure at levels well below those causing cellular toxicity. ${ }^{48}$ However, an epidemiological study of reproductive hormones in the low range of exposure levels did not find any association between mercury and inhibin B levels. ${ }^{27}$ The diet among Greenlandic Inuit is mainly based on seafood and fish that contain polyunsaturated fatty acids (PUFAs). Authors have reported that levels of omega-3 PUFAs in human sperm are positively correlated with semen characteristics ${ }^{49-52}$ and our positive association between mercury and inhibin B among Greenlandic Inuit may be due to their higher consumption of PUFAs through diet. Alternatively, the association may be a random result emerging from multiple testing. In any case, the present study does not provide support to the hypothesis that environmental exposure to mercury causes adverse effects on human semen characteristics and male reproductive hormones.

In a cohort of spouses to pregnant women, subfertile men are underrepresented and sterile men are not presented at all. This may contribute to an underestimation of the effect, in particular if the effect is strong among vulnerable and marginal among nonvulnerable. However, considering mercury an yes/no type of response is not expected and the time-to-pregnancy design has proved effective in detecting effects of occupational toxic exposures of both men and women. ${ }^{53}$ Moreover, our results are supported by other studies that have examined the same association among infertility clients. $^{24,25}$

The participation rate was low in two of the three regions, but since the men had no knowledge about their blood mercury concentration selection bias is not likely. Some individuals may suspect having low semen quality, if the couple or close family members have experienced difficulties in conceiving. It is though unlikely that the majority has knowledge about their semen quality and reproductive hormones. 


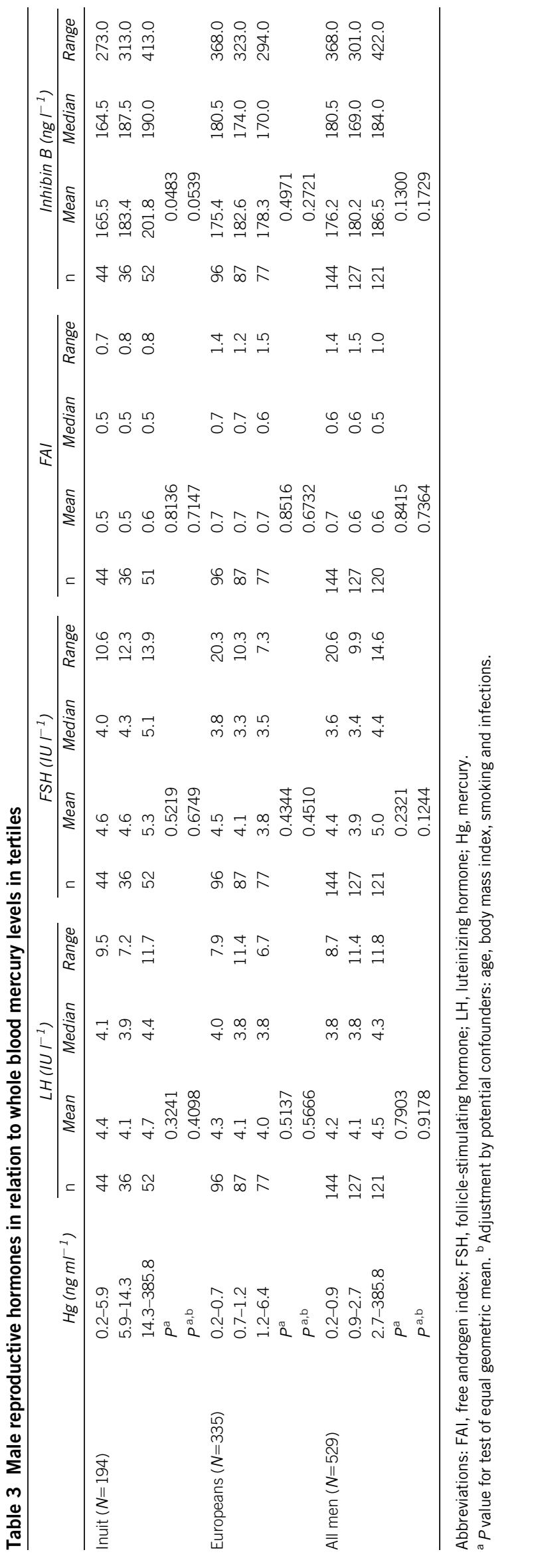

Strengths of the study include a large study population, large exposure contrast within and between countries, quality assurance of semen and mercury analyses, blinding and those data were obtained on both semen characteristics and reproductive hormones.

In in vitro studies, mercury leads to decreased sperm motility, viability, dysfunction and induced DNA breaks in the spermatozoa. ${ }^{12-15}$ Animal studies suggest that mercury affects the male reproductive organs. Mice aged 12 weeks were given mercury at a dose of $4 \mathrm{mg} \mathrm{kg}^{-1}$ for 12 weeks by gavage. The treatment resulted in a decrease in the epididymal sperm number and testicular weight. ${ }^{18}$ Impaired spermatogenesis and decreased testosterone levels were observed in 7week-old rats treated with methylmercuric chloride by subcutaneous injection at a dose of $10 \mathrm{mg} \mathrm{kg}^{-1}$ day $^{-1}$ for 8 days. ${ }^{20}$ Adult monkeys with blood mercury levels around $2000 \mathrm{ng} \mathrm{ml}^{-1}$, had a decreased sperm motility and sperm swimming speed, and increased abnormal sperm tail morphology. ${ }^{17}$ Intraperitoneal mercury exposure at $1 \mathrm{mg} \mathrm{kg}^{-1}$ resulted in adverse effects on fertility among 7-week-old mice. ${ }^{16}$ The animals and seminal fluids were exposed to significantly higher concentrations of mercury than observed in the present study. However, decreased testosterone levels were reported in another rat experiment, where the animals had mean blood mercury levels of $30.8 \mathrm{ng}$ per $\mathrm{ml}^{54}$ and Boujbiha et al. ${ }^{19}$ observed oxidative stress and significant variations of the testosterone levels among 3-month-old rats with blood mercury concentrations of 94.3 and $176.5 \mathrm{ng} \mathrm{ml}^{-1}$. We did not find effects on male reproductive function at levels close to what have produced effects in animal studies (30.8 and $94.3 \mathrm{ng} \mathrm{ml}^{-1}$ ). The prenatal period is more sensitive to mercury exposure when considering other health outcomes, ${ }^{2,55,56}$ perhaps this is also valid for reproductive outcomes measured later in life.

Several other papers examining the effect of mercury on human semen quality in similar dose ranges support the lack of association in the present study. Rignell-Hydbom et al. ${ }^{26}$ (2007) did not find any association between methylmercury $(\mathrm{MeHg})$ and semen outcomes among Swedish fishermen having blood mercury concentrations between 0.1 and $17 \mathrm{ng} \mathrm{ml}^{-1}$ with median at $2.3 \mathrm{ng} \mathrm{ml}^{-1}$. Among Asian males with no known cause for infertility, Chia et al. ${ }^{24}$ investigated differences between mercury concentrations in men having $<40 \%$ motile sperm and those having $\geqslant 40 \%$. They did not find any significant differences between the mercury levels which were $1.8 \mathrm{ng} \mathrm{ml}^{-1}$ vs. $1.9 \mathrm{ng} \mathrm{ml}^{-1}$ in the two groups. Leung et al. ${ }^{25}$ found that men from Hong Kong who had blood mercury concentrations $\geqslant 10 \mathrm{ng} \mathrm{ml}^{-1}$ had lower sperm concentration, percentage of morphologically normal sperm and percentage of motile sperm, than men who had blood mercury concentrations less than $10 \mathrm{ng} \mathrm{ml}^{-1}$. The results were not significant, possibly because of the small sample size in each group $(n=37$ vs. 21$)$. In studies of men with higher exposure levels, Choy et al. ${ }^{21}$ found that infertile Asian men had higher blood mercury levels than the control group. The mean mercury level in the infertile group was 8.1 and $6.3 \mathrm{ng} \mathrm{ml}^{-1}$ in the control group. Another study also observed a negative association between seminal fluid mercury concentrations and abnormal semen morphology and motility among 111 men from Hong Kong. The men had a mean blood mercury concentration of $8.3 \mathrm{ng} \mathrm{ml}^{-1}$, which was almost twice as high as the one in seminal fluid. The overall percentages of motile spermatozoa and sperm concentration were not correlated with blood mercury concentrations. $^{29}$

The literature regarding exposure to mercury and male reproductive hormone levels is sparse. In the present study, no significant associations were found between mercury exposure and $\mathrm{FSH}, \mathrm{LH}$, 
Table 4 Measures for testosterone and LH $\times$ testosterone in relation to whole blood mercury levels in tertiles

\begin{tabular}{|c|c|c|c|c|c|c|c|c|c|}
\hline & \multirow[b]{2}{*}{$\mathrm{Hg}\left(n g m l^{-1}\right)$} & \multicolumn{4}{|c|}{ Testosterone $\left(\mathrm{nmol} I^{-1}\right)$} & \multicolumn{4}{|c|}{ LH×testosterone } \\
\hline & & $\mathrm{n}$ & Mean & Median & Range & $n$ & Mean & Median & Range \\
\hline \multirow[t]{5}{*}{ Inuit ( $N=194)$} & $0.2-5.9$ & 44 & 14.8 & 14.1 & 16.6 & 44 & 65.7 & 55.4 & 186.2 \\
\hline & $5.9-14.3$ & 36 & 13.4 & 13.2 & 21.3 & 36 & 55.8 & 56.3 & 159.5 \\
\hline & $14.3-385.8$ & 52 & 15.5 & 15.6 & 23.5 & 52 & 73.8 & 71.9 & 214.7 \\
\hline & $P^{a}$ & \multirow{2}{*}{\multicolumn{4}{|c|}{0.1785}} & \multicolumn{4}{|c|}{0.1048} \\
\hline & $P^{\mathrm{a}, \mathrm{b}}$ & & & & & & 0.1549 & & \\
\hline \multirow[t]{5}{*}{ Europeans ( $N=335$ ) } & $0.2-0.7$ & 96 & 15.9 & 16.1 & 24.8 & 96 & 70.0 & 65.3 & 164.1 \\
\hline & $0.7-1.2$ & 87 & 16.1 & 15.4 & 31.7 & 87 & 69.5 & 58.7 & 233.1 \\
\hline & $1.2-6.4$ & 77 & 15.9 & 15.6 & 28.8 & 77 & 66.0 & 58.0 & 245.0 \\
\hline & $p^{a}$ & \multirow{2}{*}{\multicolumn{3}{|c|}{$\begin{array}{l}0.9873 \\
0.8371\end{array}$}} & \multicolumn{5}{|c|}{0.6983} \\
\hline & $P^{\mathrm{a}, \mathrm{b}}$ & & & & & & 0.8714 & & \\
\hline \multirow[t]{5}{*}{ All men ( $N=529)$} & $0.2-0.9$ & 144 & 15.9 & 15.8 & 25.9 & 144 & 68.7 & 59.3 & 176.1 \\
\hline & $0.9-2.7$ & 127 & 15.8 & 15.3 & 31.6 & 127 & 67.3 & 58.1 & 233.1 \\
\hline & $2.7-385.8$ & 121 & 14.8 & 14.3 & 30.9 & 121 & 67.3 & 61.3 & 250.6 \\
\hline & $P^{a}$ & \multicolumn{4}{|c|}{0.8459} & \multicolumn{4}{|c|}{0.8681} \\
\hline & $P^{\mathrm{a}, \mathrm{b}}$ & \multicolumn{4}{|c|}{0.7963} & \multicolumn{4}{|c|}{0.9217} \\
\hline
\end{tabular}

Abbreviations: LH, luteinizing hormone; $\mathrm{Hg}$, mercury.

${ }^{\text {a }} P$ value for test of equal geometric mean. ${ }^{\mathrm{b}}$ Adjustment by potential confounders: age, body mass index, smoking and infections.

Table 5 Trends for logarithm transformed semen and blood outcomes with logarithm transformed continuous mercury exposure (In $\mathrm{Hg}$ )

\begin{tabular}{|c|c|c|c|c|c|c|c|c|c|}
\hline & \multicolumn{3}{|c|}{ Inuit $(\mathrm{n}=194)$} & \multicolumn{3}{|c|}{ Europeans $(n=335)$} & \multicolumn{3}{|c|}{ All men $(n=529)$} \\
\hline & $\mathrm{n}$ & $\beta$ & $(95 \% \mathrm{Cl})$ & $\mathrm{n}$ & $\beta$ & $(95 \% \mathrm{Cl})$ & $\mathrm{n}$ & $\beta$ & $(95 \% \mathrm{Cl})$ \\
\hline Semen volume $(\mathrm{ml})^{\mathrm{a}}$ & 173 & -0.049 & $(-0.112-0.016)$ & 302 & 0.053 & $(-0.042-0.148)$ & 475 & -0.018 & $(-0.052-0.015)$ \\
\hline Total sperm count $\left(\times 10^{6}\right)^{a}$ & 173 & -0.105 & $(-0.233-0.024)$ & 300 & -0.034 & $(-0.242-0.173)$ & 473 & -0.062 & $(-0.133-0.009)$ \\
\hline Sperm concentration $\left(\times 10^{6} \mathrm{ml}^{-1}\right)$ & 194 & -0.034 & $(-0.139-0.070)$ & 333 & -0.054 & $(-0.233-0.125)$ & 527 & -0.022 & $(-0.081-0.038)$ \\
\hline Normal morphology (\%) & 192 & -0.017 & $(-0.091-0.057)$ & 325 & -0.037 & $(-0.153-0.078)$ & 517 & -0.013 & $(-0.052-0.027)$ \\
\hline Sperm motility $\mathrm{C}+\mathrm{D}(\%)^{\mathrm{b}}$ & 191 & 0.043 & $(-0.007-0.094)$ & 307 & -0.011 & $(-0.108-0.086)$ & 498 & 0.027 & $(-0.021-0.076)$ \\
\hline $\mathrm{LH}\left(\mathrm{IU} \mathrm{I}^{-1}\right)$ & 132 & 0.025 & $(-0.034-0.084)$ & 260 & -0.054 & $(-0.138-0.030)$ & 392 & -0.001 & $(-0.048-0.048)$ \\
\hline $\mathrm{FSH}\left(\mathrm{IU} \mathrm{I^{-1 } )}\right.$ & 131 & 0.040 & $(-0.029-0.109)$ & 260 & -0.044 & $(-0.148-0.059)$ & 391 & 0.015 & $(-0.044-0.073)$ \\
\hline FAl & 131 & -0.009 & $(-0.054-0.035)$ & 260 & -0.042 & $(-0.111-0.028)$ & 391 & -0.017 & $(-0.055-0.021)$ \\
\hline Inhibin $B\left(\left.n g\right|^{-1}\right)$ & 132 & 0.074 & $(0.021-0.126)$ & 260 & 0.032 & $(-0.046-0.111)$ & 392 & 0.067 & $(0.024-0.110)$ \\
\hline Testosterone $\left(\mathrm{nmol} \mathrm{I}^{-1}\right)$ & 132 & -0.012 & $(-0.061-0.036)$ & 260 & 0.011 & $(-0.081-0.059)$ & 392 & -0.003 & $(-0.039-0.034)$ \\
\hline LHXtestosterone & 132 & 0.013 & $(-0.069-0.095)$ & 260 & -0.036 & $(-0.157-0.084)$ & 392 & -0.003 & $(-0.071-0.065)$ \\
\hline
\end{tabular}

Abbreviations: $\mathrm{Cl}$, confidence interval; FAI, free androgen index; FSH, follicle-stimulating hormone; LH, luteinizing hormone.

${ }^{\text {a }}$ Samples with spillage were excluded. ${ }^{\mathrm{b}}$ Analysis was restricted to samples analyzed within $1 \mathrm{~h}$ after collection.

FAI, testosterone and $\mathrm{LH} \times$ testosterone. These findings are supported by others. ${ }^{25,27,28}$

\section{CONCLUSION}

Findings of this study do not lend support to the hypothesis that environmental mercury exposure affects male fecundity in terms of semen quality and serum levels of reproductive hormones. A positive association between mercury and inhibin B may be caused by higher levels of PUFAs in diet among Greenlandic Inuit or may be a random finding. From a public health perspective these overall findings are reassuring, even within a highly exposed population as Greenlandic Inuit.

\section{AUTHOR CONTRIBUTIONS}

EM, IOS and JPB contributed to design of the analyses. GT and AG were responsible for conventional semen analysis and AG for lab analyses of hormones. BAGJ and TL were responsible for laboratory analyses of mercury. Data analysis was performed by EM and JLM. The first version of the manuscript was drafted by EM and JPB and all authors provided substantial intellectual contributions and approved the final version of the manuscript.

\section{COMPETING FINANCIAL INTERESTS}

All authors declare that there are no competing financial interests.

\section{ACKNOWLEDGMENTS}

The project was supported by grants from European Commission to the 5th and 7th Framework Programme (No. QLK4-CT-2001_00202 and FP7-ENV2008-1 No. 226217), the Danish Research Council (No. 10-082745) and the Reprosund project. The immense amount of work in creating cohorts and collecting data in Greenland, Ukraine and Poland by Henning S. Pedersen, Valentyna Zvyezday and Jan K. Ludwicki is highly appreciated.

1 Wirth JJ, Mijal RS. Adverse effects of low level heavy metal exposure on male reproductive function. Syst Biol Reprod Med 2010; 56: 147-67. 
2 Clarkson TW, Magos L. The toxicology of mercury and its chemical compounds. Crit Rev Toxicol 2006; 36: 609-62.

3 AMAP. AMAP Assessment 2009: Human Health in the Arctic. Oslo: Arctic Monitoring and Assessment Programme (AMAP); 2009.

4 Johansen P, Mulvad G, Pedersen HS, Hansen JC, Riget F. Human accumulation of mercury in Greenland. Sci Total Environ 2007; 377: 173-8.

5 IPCS. Concise International Chemical Assessment Document 50: Elemental mercury and inorganic mercury compounds: human health aspects. Geneva: World Health Organization; 2003.

6 Johansen P, Pars T, Bjerregaard P. Lead, cadmium, mercury and selenium intake by Greenlanders from local marine food. Sci Total Environ 2000; 245: 187-94.

7 JECFA. Methylmercury. In: JECFA, editor. Safety Evaluation of Certain Food Additives and Contaminants. Report of the 61st Joint FAO/WHO Expert Committee on Food Additives. Geneva: World Health Organization, International Programme on Chemical Safety; 2004.

8 Gibb H, Haver C, Kozlov K, Centeno JA, Jurgenson V et al. Biomarkers of mercury exposure in two eastern Ukraine cities. J Occup Environ Hyg 2011; 8: 187-93.

9 Lech T, Sadlik JK. Total mercury levels in human autopsy materials from a nonexposed Polish population. Arch Environ Health 2004; 59: 50-4.

10 Marzec Z, Schlegel-Zawadzka M. Exposure to cadmium, lead and mercury in the adult population from Eastern Poland, 1990-2002. Food Addit Contam 2004; 21: 96370.

11 AMAP. AMAP Assessment 2002: Heavy Metals in the Arctic. Oslo: Arctic Monitoring and Assessment Programme (AMAP); 2004.

12 Arabi M, Heydarnejad MS. In vitro mercury exposure on spermatozoa from normospermic individuals. Pak J Biol Sci 2007; 10: 2448-53.

13 Mohamed MK, Lee WI, Mottet NK, Burbacher TM. Laser light-scattering study of the toxic effects of methylmercury on sperm motility. J Androl 1986; 7: 11-5.

14 Ernst E, Lauritsen JG. Effect of organic and inorganic mercury on human sperm motility. Pharmacol Toxicol 1991; 68: 440-4

15 Rao MV. Toxic effects of methylmercury on spermatozoa in vitro. Experientia 1989; 45: 985-7.

16 Lee IP, Dixon RL. Effects of mercury on spermatogenesis studied by velocity sedimentation cell separation and serial mating. J Pharmacol Exp Ther 1975; 194: 171-81.

17 Mohamed MK, Burbacher TM, Mottet NK. Effects of methyl mercury on testicular functions in Macaca fascicularis monkeys. Pharmacol Toxicol 1987; 60: 29-36.

18 Orisakwe OE, Afonne OJ, Nwobodo E, Asomugha L, Dioka CE. Low-dose mercury induces testicular damage protected by zinc in mice. Eur J Obstet Gynecol Reprod Biol 2001; 95: 92-6.

19 Boujbiha MA, Hamden K, Guermazi F, Bouslama A, Omezzine A et al. Testicular toxicity in mercuric chloride treated rats: association with oxidative stress. Reprod Toxicol 2009; 28: 81-9.

20 Homma-Takeda S, Kugenuma Y, Iwamuro T, Kumagai Y, Shimojo N. Impairment of spermatogenesis in rats by methylmercury: involvement of stage- and cell-specific germ cell apoptosis. Toxicology 2001; 169: 25-35.

21 Choy CM, Lam CW, Cheung LT, Briton-Jones CM, Cheung LP et al. Infertility, blood mercury concentrations and dietary seafood consumption: a case-control study. BJOG 2002; 109: 1121-5.

22 Dickman MD, Leung KM. Mercury and organochlorine exposure from fish consumption in Hong Kong. Chemosphere 1998; 37: 991-1015.

23 Keck C, Bergmann M, Ernst E, Muller C, Kliesch S et al. Autometallographic detection of mercury in testicular tissue of an infertile man exposed to mercury vapor. Reprod Toxicol 1993; 7: 469-75.

24 Chia SE, Ong CN, Lee ST, Tsakok FH. Blood concentrations of lead, cadmium, mercury, zinc, and copper and human semen parameters. Arch Androl 1992; 29: 177-83.

25 Leung TY, Choy CM, Yim SF, Lam CW, Haines CJ. Whole blood mercury concentrations in sub-fertile men in Hong Kong. Aust N Z J Obstet Gynaecol 2001; 41: 75-7.

26 Rignell-Hydbom A, Axmon A, Lundh T, Jonsson BA, Tiido T et al. Dietary exposure to methyl mercury and PCB and the associations with semen parameters among Swedish fishermen. Environ Health 2007; 6: 14

27 Meeker JD, Rossano MG, Protas B, Padmanahban V, Diamond MP et al. Environmental exposure to metals and male reproductive hormones: circulating testosterone is inversely associated with blood molybdenum. Fertil Steril 2010; 93: 130-40.

28 McGregor AJ, Mason HJ. Occupational mercury vapour exposure and testicular, pituitary and thyroid endocrine function. Hum Exp Toxicol 1991; 10: 199-203.

29 Choy CM, Yeung QS, Briton-Jones CM, Cheung CK, Lam CW et al. Relationship between semen parameters and mercury concentrations in blood and in seminal fluid from subfertile males in Hong Kong. Fertil Steril 2002; 78: 426-8.

30 Rachootin $\mathrm{P}$, Olsen J. The risk of infertility and delayed conception associated with exposures in the Danish workplace. J Occup Med 1983; 25: 394-402.
31 Cordier S, Deplan F, Mandereau L, Hemon D. Paternal exposure to mercury and spontaneous abortions. Br J Ind Med 1991; 48: 375-81.

32 Cole DC, Wainman B, Sanin LH, Weber JP, Muggah H et al. Environmental contaminant levels and fecundability among non-smoking couples. Reprod Toxicol 2006; 22: 13-9.

33 Alcser KH, Brix KA, Fine LJ, Kallenbach LR, Wolfe RA. Occupational mercury exposure and male reproductive health. Am J Ind Med 1989; 15: 517-29.

34 Lauwerys R, Roels H, Genet P, Toussaint G, Bouckaert A et al. Fertility of male workers exposed to mercury vapor or to manganese dust: a questionnaire study. Am J Ind Med 1985; 7: 171-6.

35 Toft G, Axmon A, Giwercman A, Thulstrup AM, Rignell-Hydbom A et al. Fertility in four regions spanning large contrasts in serum levels of widespread persistent organochlorines: a cross-sectional study. Environ Health 2005; 4: 26.

36 Giwercman A, Richthoff J, Hjollund H, Bonde JP, Jepson K et al. Correlation between sperm motility and sperm chromatin structure assay parameters. Fertil Steril 2003; 80: 1404-12.

37 Groome NP, Illingworth PJ, O'Brien M, Pai R, Rodger FE et al. Measurement of dimeric inhibin B throughout the human menstrual cycle. J Clin Endocrinol Metab 1996; 81: 1401-5.

38 Toft G, Rignell-Hydbom A, Tyrkiel E, Shvets M, Giwercman A et al. Semen quality and exposure to persistent organochlorine pollutants. Epidemiology 2006; 17: 450-8.

39 World Health Organization. Laboratory Manual for the Examination of Human Semen and Sperm—Cervical Mucus Interaction. Cambridge/New York: Cambridge University Press; 1999.

40 Toft G, Rignell-Hydbom A, Tyrkiel E, Shvets M, Giwercman A. Quality control workshops in standardization of sperm concentration and motility assessment in multicentre studies. Int J Androl 2005; 28: 144-9.

41 Giwercman AH, Rignell-Hydbom A, Toft G, Rylander L, Hagmar L et al. Reproductive hormone levels in men exposed to persistent organohalogen pollutants: a study of inuit and three European cohorts. Environ Health Perspect 2006; 114: 1348-53.

42 Bonde JP, Toft G, Rylander L, Rignell-Hydbom A, Giwercman A et al. Fertility and markers of male reproductive function in Inuit and European populations spanning large contrasts in blood levels of persistent organochlorines. Environ Health Perspect 2008; 116: 269-77.

43 Jensen TK, Andersson AM, Jorgensen N, Andersen AG, Carlsen E et al. Body mass index in relation to semen quality and reproductive hormones among 1,558 Danish men. Fertil Steril 2004; 82: 863-70.

44 Ramlau-Hansen CH, Thulstrup AM, Aggerholm AS, Jensen MS, Toft G et al. Is smoking a risk factor for decreased semen quality? A cross-sectional analysis. Hum Reprod 2007; 22: 188-96.

45 Hassan MA, Killick SR. Effect of male age on fertility: evidence for the decline in male fertility with increasing age. Fertil Steril 2003; 79: 1520-7.

46 Mamsen LS, Lutterodt MC, Andersen EW, Skouby SO, Sorensen KP et al. Cigarette smoking during early pregnancy reduces the number of embryonic germ and somatic cells. Hum Reprod 2010; 25: 2755-61.

47 Gaur DS, Talekar MS, Pathak VP. Alcohol intake and cigarette smoking: impact of two major lifestyle factors on male fertility. Indian J Pathol Microbiol 2010; 53: 35-40.

48 Monsees TK, Franz M, Gebhardt S, Winterstein U, Schill WB et al. Sertoli cells as a target for reproductive hazards. Andrologia 2000; 32: 239-46.

49 Attaman JA, Toth TL, Furtado J, Campos H, Hauser R et al. Dietary fat and semen quality among men attending a fertility clinic. Hum Reprod 2012; 27: 1466-74.

50 Aksoy Y, Aksoy H, Altinkaynak K, Aydin HR, Ozkan A. Sperm fatty acid composition in subfertile men. Prostaglandins Leukot Essent Fatty Acids 2006; 75: 75-9.

51 Safarinejad MR. Effect of omega-3 polyunsaturated fatty acid supplementation on semen profile and enzymatic anti-oxidant capacity of seminal plasma in infertile men with idiopathic oligoasthenoteratospermia: a double-blind, placebo-controlled, randomised study. Andrologia 2011; 43: 38-47

52 Olsen J, Ramlau-Hansen $\mathrm{CH}$. Dietary fats may impact semen quantity and quality. Asian J Androl 2012; 14: 511-2.

53 Bonde JP, Joffe M, Sallmen M, Kristensen P, Olsen J et al. Validity issues relating to time-to-pregnancy studies of fertility. Epidemiology 2006; 17: 347-9.

54 Moussa H, Hachfi L, Trimeche M, Najiar MF, Sakly R. Accumulation of mercury and its effects on testicular functions in rats intoxicated orally by methylmercury. Andrologia 2011; 43: 23-7.

55 Bakir F, Damluji SF, Amin-Zaki L, Murtadha M, Khalidi A et al. Methylmercury poisoning in Iraq. Science 1973; 181: 230-41.

56 Grandjean P, Weihe P, White RF, Debes F, Araki S et al. Cognitive deficit in 7-year-old children with prenatal exposure to methylmercury. Neurotoxicol Teratol 1997; 19: 417-28. 